\title{
O EMPODERAMENTO NA MEDIAÇÃO ESCOLAR DE PARES: CONCRETIZAÇÃO DE DIRETOS FUNDAMENTAIS E DA DIGNIDADE DA PESSOA HUMANA.
}

\section{EMPOWERMENT IN SCHOOL COUPLE MEDIATION: REALIZATION OF FUNDAMENTAL DIRECT AND DIGNITY OF THE HUMAN PERSON}

\author{
${ }^{1}$ Maria Hortência Cardoso Lima
}

\section{RESUMO}

O presente trabalho tem o objetivo de analisar a implementação da mediação no ambiente escolar com vistas à promoção do empoderamento entre os pares envolvidos no processo. Tal prática dissemina na sociedade a educação social, o exercício da cidadania e a preparação para a superação dos conflitos que afligem a escola e a sociedade de uma forma geral. Os direitos fundamentais estão, expressamente, inseridos na Constituição Brasileira como direitos basilares a serem promovidos pelo Estado, vinculados diretamente à manutenção do Estado Democrático de Direito. A dignidade humana tem por pressuposto o reconhecimento e a proteção desses direitos fundamentais.

Palavras-chave: Mediação, Empoderamento, Direitos fundamentais, Dignidade humana

\begin{abstract}
This study aims to analyze the implementation of mediation in the school environment with a view to promoting empowerment among peers involved. This practice spread in society social education, citizenship and preparation for overcoming the conflicts that afflict the school and society in general . Fundamental rights are expressly inserted in the Brazilian Constitution as fundamental rights to be promoted by the state, directly linked to the maintenance of the democratic rule of law. Human dignity aims the recognition and protection of these fundamental rights.
\end{abstract}

Keywords: Mediation, Empowerment, Fundamental rights, Human dignity

\footnotetext{
${ }^{1}$ Bacharelado em Direito pela Faculdade Estácio de Sergipe, Aracaju, (Brasil). Assessora-Conciliadora do Centro de Solução de Conflitos - CEJUSC do Tribunal de Justiça - Sergipe. E-mail: tutortreinamento@gmail.com
} 


\title{
INTRODUÇÃO
}

\begin{abstract}
"Uma Cultura de Paz é um conjunto de valores, atitudes, tradições, comportamentos e estilos de vida baseados: a) No respeito à vida, no fim da violência e na promoção e prática da não violência por meio da educação, do diálogo e da cooperação (...)" (Declaração da ONU, artigo $1^{\circ}, 1999$ ).
\end{abstract}

Não há ambiente mais propício ao investimento de politicas públicas que se voltem para a construção de processos de diálogos e do empoderamento ao cidadão do que o ambiente escolar.

Da escola, se projetam para a sociedade os comportamentos, sistema cultural dos grupos sociais e ensinamentos ali apregoados e estimulados. A escola, definitivamente, é um "espaço social destinado à construção da personalidade e da cidadania, além da promoção de educação voltada para a conscientização cívica e social de jovens". (ORSINI, 2012, p.191).

Por sua diversidade de relações, a escola apresenta ambiente rico nos mais diversos tipos de relações e conflitos, seja entre alunos, professores, coordenação ou comunidade.

O conflito ocorre quando atividades incompatíveis acontecem. Conflito, para o dicionário online significa divergência, ausência de concordância ou ausência de entendimento, sentido de oposição de interesses, oposição de opiniões. Morton Deutsch, escritor americano, complementa informando que os conflitos podem ser originados em uma pessoa (inter ou intrapessoais), em uma coletividade(intercoletivos) ou entre duas ou mais nações (internacionais). (DEUTSCH, 2014).

O conflito, contudo, caracteriza-se como atos inerentes da convivência humana, vez que em sociedade o homem sempre encontrará incompatibilidades de entendimentos, sendo certo que "desacordos e problemas podem surgir em quase todos os relacionamentos". (MOORE, 1998, p.22).

Uma outra definição muito interessante apresenta o conflito como "uma divergência de perspectivas, percebida como geradora de tensão por, pelo menos, uma das partes envolvidas numa determinada interação, e que pode ou não traduzir-se numa incompatibilidade de objetivos". (DIMAS; LOURENÇO; MIGUEZ, 2007, p.38).

$\mathrm{O}$ ambiente escolar abriga diferentes relacionamentos diários, com grande amplitude de pessoas envolvidas, de forma bastante diversificada, a exemplo de alunos e pais de alunos, professores, funcionários, coordenação, direção e comunidade em geral.

O confronto de interesses próprios das relações que se desenvolvem rotineiramente desembocam, muitas vezes, nos mais diferentes tipos de conflitos. Estes, por sua vez, ganham 
soluções as mais diversas. Contudo, nos últimos anos, em função do grande grau de litigiosidade presente na nossa sociedade, as soluções encontradas nem sempre tem trazido satisfação às partes envolvidas e o desenrolar dos conflitos, em muitas ocasiões, terminam em noticiários de televisão com desfecho trágico.

Deutsch (2014, p. 43), escritor americano, defende, contudo, a concepção de carácteres construtivos e destrutivos existentes na abordagem dos conflitos. Defende a situação de caráter cooperativo do conflito "como uma em que os objetivos dos participantes estão tão ligados que qualquer participante os alcançará se, e somente se, os outros com quem está ligado também o podem fazer". Enquanto que a forma destrutiva do conflito é definida como sendo uma aquisição interdependente e correlativa, em grau de competição, “onde um participante pode alcançar seu objetivo se, e somente se, os outros com quem está ligado não o podem fazer".

A cientista política norte-americana, Mary Parker Follet, no início do século XIX, tinha uma percepção otimista do conflito, defendendo que havia três possibilidades de solução para os conflitos: dominação, compromisso e integração. $\mathrm{Na}$ primeira forma, uma parte domina a outra; na segunda, ambas abrem mão de algum elemento que valorizam em busca de um acordo; e, na última forma, a integração apresenta um manuseio maior do conflito de forma que ocorra a criação de novas perspectivas de solução em que ambos possam ter seus interesses e objetivos atendidos. (FOLLET, 1996, p. 67-68).

As notícias têm sinalizado que, no ambiente escolar, a segunda alternativa (caráter destrutivo) tem sido aplicada e com alguns resultados desastrosos.

O objetivo deste artigo é defender a prática da mediação no ambiente escolar, com vistas a empoderar os indivíduos e promover a transformação da abordagem dos conflitos de um enfoque destrutivo para o construtivo, capacitando os agentes para construir soluções conjuntas para os conflitos. Espera-se que os que se envolvam em algum conflito, na escola, possam desenvolver o conhecimento do empoderamento e a possibilidade de solução de conflitos em caráter cooperativo, prospectivo e positivo. Isso representa o alcance de objetivos mais amplos, conforme os artigos constitucionalmente expostos na Constituição Federal de 1988, de Direitos à Educação e Cidadania, direitos sociais e políticos, sinalizando o alcance de direitos fundamentais legítimos para o cidadão. Sua realização envolve o atendimento a princípios fundamentais do ser e a dignidade da pessoa humana, princípio intrínseco em todo o ordenamento constitucional. Cabe ao Estado sua promoção, constando tais direitos no âmbito dos direitos prestacionais. 
Empoderar, de acordo com o dicionário online disponível é um termo substantivo, derivado da palavra em inglês empower, com significado de "dar ou delegar poderes, emancipar $\mathrm{ou}$ ainda, conceder autonomia $\mathrm{ou}$ autoridade". (http://www.meusdicionarios.com.br/empowerment, acesso em 21/03/2016).

No processo da mediação o empoderamento das partes é visto como um dos benefícios que essa metodologia de Resolução Alternativa de Disputas proporciona, significando "a busca pela restauração do senso de valor e poder da parte para que esta esteja apta a melhor dirimir futuros conflitos". (AZEVEDO, 2015, p. 142).

O desenvolvimento desta capacitação nos integrantes do ambiente escolar, atende aos comandos constitucionais da Lei Maior de 1988 e possui o escopo defendido pelos Constituintes de proporcionar o desenvolvimento pleno da pessoa, preparando-a para o exercício da cidadania e sua qualificação.

A constituição de 1988, trata pela primeira vez, com relevância, a temática dos direitos fundamentais, explicitando direitos sociais, onde se insere a educação, e direitos políticos, que dizem respeito à formação da cidadania e radicam tanto no principio da dignidade da pessoa humana como nos princípios que consagram o Estado social de Direito. (SARLET, 2006, p.28).

A dignidade da pessoa humana alcança a grande amplitude de direitos fundamentais dispostos na Constituição Brasileira de 1988, sendo a observância de tais direitos uma consagração desse princípio maior constitucional.

\footnotetext{
(...)a dignidade da pessoa humana engloba necessariamente o respeito e a proteção da integridade física e corporal do individuo, do que decorrem, por exemplo, a proibição da pena de morte da tortura, das penas de natureza corporal, da utilização da pessoa humana para experiências científicas, limitações aos meios de prova(utilização de detector de mentiras), regras relativas aos transplantes de órgãos, etc. Além desses fatores também são associados à proteção da dignidade a garantia de ser assegurada uma existência digna (direitos sociais, trabalho, seguridade social, etc), bem como tudo que esteja associado ao desenvolvimento livre de sua personalidade (liberdade de culto, de consciência, proteção da intimidade, da honra...). (SARLET, 2006. p. 103).
}

Atendendo a esses requisitos fundamentais e de satisfação, atinge-se a dignidade da pessoa humana, no ambiente escolar, posto tratar-se de princípio constitucional a ser amplamente buscado para todos e por todos os cidadãos.

A metodologia adotada será a pesquisa bibliográfica qualitativa, desenvolvida a partir de material já elaborado, baseada principalmente em livros e artigos científicos. (GIL, 2008). 


\section{A QUESTÃO DA VIOLÊNCIA NO AMBIENTE ESCOLAR}

As múltiplas relações pessoais presentes no ambiente escolar, sempre proporcionaram uma diversidade de conflitos. Na França, a situação passou a ser estudada por sociólogos, que ao apresentar as questões e situações vivenciadas desde o século XIX, com explosões de violências periódicas, demonstrando que tais fenômenos não são relativamente novos, parecem retratar o ambiente da nossa escola no Brasil, face a semelhança das situações vividas e apontadas.

Os dados, naquela sociedade francesa, dos anos 50 e 60, dividem a situação de violência em quatro estágios: um primeiro com violências bem mais graves, com homicídios, estupros e agressões com armas, ataques ou insultos dirigidos a professores, o que contribui com uma angústia social. Em segunda análise os dados apontam um crescimento de jovens, cada vez mais novos, envolvidos nos conflitos, em média de 8 a 13 anos; em terceiro plano, surgem as “intrusões externas", que se configuram como alunos de outras escolas, pais ou amigos de alunos ou outras pessoas estranhas ao ambiente, onde a escola é tão somente o local da violência; e, por fim, em quarto plano aparecem os docentes e corpo administrativo da escola que sofrem repetidos atos de stress, que apesar de não violentos, se somam ao longo das relações e provocam um estado permanente de sobressaltos e de ameaças. (CHARLOT, 2002).

Apesar da realidade apresentada ser a francesa, a semelhança do quadro apresentado com a realidade brasileira, convida-nos a um olhar mais interessado para o deslinde da conclusão ali apresentada. Estudando os conflitos, o autor traz a análise de sociólogos e estudiosos da educação que afirmam, inicialmente, a necessidade de apresentar distinções conceituais sobre a violência na escola, destrinchando-a da seguinte forma: a) violência na escola, como sendo a que se produz dentro do espaço escolar, sem, contudo, estar ligada às atividades naturais da instituição, a exemplo das disputas de bairro ou entre alunos de escolas diferentes, a escola é tão somente o local onde ocorre a disputa; b) violência à escola, que são os conflitos próprios, inerentes às atividades da instituição (exemplo, discussões entre alunos professores, questões sobre notas, composição das salas, etc); No primeiro caso, a escola, pode se socorrer de sistemas de vigilância e atividades outras que proporcione mais segurança. Para o segundo caso, as ações devem ser refletidas, posto que devem visar ao controle dos conflitos já que inerentes à conduta humana, o que os tornam contínuos.

O conflito faz parte do processo de se testar e avaliar alguém e pode prevenir estagnações, estimular interesses e curiosidades. É o meio pelo qual os problemas se 
manifestam e a solução pode significar mudanças bastante positivas. (DEUTSCH, 2014, p. $34)$.

Defendem, os sociólogos franceses, a ideia de que os conflitos não devem desaparecer, mas sim serem contidos. A violência que representa a vontade de destruir, aviltar e atormentar, é a que deve ser combatida, e é a que causa mais problemas, ainda mais por se reproduzir em ambiente em que se inscreve na ordem da linguagem e da troca simbólica e não da força física. Isso significa que o que se torna necessário é o controle do conflito por meio do diálogo, da palavra e não pela violência. O que está em jogo não é tão somente a violência mas sim a capacidade da escola e seus agentes conseguirem superar e gerir as situações conflituosas. (CHARLOT, 2002).

Nesse contexto, falar em mediação no ambiente escolar faz muito sentido, vez que este mecanismo se pauta pela recuperação de relações rompidas por intermédio da comunicação eficiente. O empoderamento, um dos escopos da mediação, se mostra muito apropriado para desenvolver-se, já em fase escolar, nas crianças e jovens, e sendo reproduzido nas escolas, por educadores e gestores e, ainda, praticado por coordenadores e servidores permitirá a oportunidade de uma gestão dos conflitos, com vistas a sua superação, por meio de um sistema de comunicação eficiente, pacífico e com excelentes resultados de melhoria de condutas.

\section{A MEDIAÇÃO, A MEDIAÇÃO DE PARES E O EMPODERAMENTO}

Mediação é um método de negociação ou de autocomposição, intermediado por um terceiro imparcial, com a finalidade de alcançar os interesses interpessoais das partes envolvidas em um conflito. O mediador não produzirá nenhuma decisão, ficando esta a cargo das partes. No processo de mediação, devem-se levar em conta os interesses anteriores ao conflito, muitas vezes considerados de forma secundária e sem importância.

A questão que se apresenta, não é o único foco da mediação, além dele outros fatores, a exemplo de relacionamentos anteriores entre os envolvidos, valores e personalidade de cada um, forma como se comunicam, devem ser foco de atuação do mediador. (AZEVEDO, 2015, p. 142).

O Manual de Mediação Judicial, difundido pelo Conselho Nacional de Justiça, organizado por André Gomma de Azevedo, define a mediação técnica judicial como sendo: 


\begin{abstract}
(...)um processo autocompositivo segundo o qual as partes em disputa são auxiliadas por uma terceira parte, neutra ao conflito, ou um painel de pessoas sem interesse na causa, para auxiliá-las a chegar a uma composição. Trata-se de uma negociação assistida ou facilitada por um ou mais terceiros na qual se desenvolve processo composto por vários atos procedimentais pelos quais o(s) terceiro(s) imparcial(is) facilita(m) a negociação entre pessoas em conflito, habilitando-as a melhor compreender suas posições e a encontrar soluções que se compatibilizam aos seus interesses e necessidades. (AZEVEDO, 2015 p.132).
\end{abstract}

Nessa definição leva-se em consideração que no ambiente judicial, outros atores participam ou interferem na gestão do conflito, além das pessoas em litigio, a exemplo de advogados e magistrados.

Outras definições são encontradas em fontes diversas, como por exemplo:

\begin{abstract}
Mediação é um meio geralmente não hierarquizado de solução de disputas em que duas ou mais pessoas, com a colaboração de um terceiro, o mediador - que deve ser apto, imparcial, independente e livremente escolhido e aceito - expõem o problema, são escutadas e questionadas, dialogam construtivamente e procuram identificar os interesses comuns, opções, e eventualmente, firmam acordo. (VASCONCELOS, 2008, p. 36).
\end{abstract}

Goldberg afirma "mediation is negotiation carried out with the assistance of a third party”. (GOLDBERG, 2003, p. 111).

Corroborando com a temática, Helena Soleto Munoz, afirma que:

la mediación es un procedimiento a través del cual um tercero imparcial ayuda a las partes en conflicto a llegar a un acuerdo. La esencia de la mediación que refleja esta definición es la autonomia de la voluntad de las partes (MUNOZ, 2009, p. 97).

Na definição de mediação no Novo CPC, lei 13105/2015, informa-se que o mediador, deve atuar, preferencialmente, nos casos em que haja vínculos anteriores entre as pessoas, quando deve auxiliá-las a compreender as questões e os interesses envolvidos no conflito, de tal forma que possam, após o restabelecimento da comunicação, construir, soluções consensuais e com benefícios mútuos. (BRASIL, Lei 13105/2015, art.165, $\S 3^{\circ}$ ).

A lei específica sobre Mediação apresenta seu conceito já no parágrafo primeiro do artigo $1^{\circ}$, assim descrevendo-a:

Considera-se mediação a atividade técnica exercida por terceiro imparcial sem poder decisório, que, escolhido ou aceito pelas partes, as auxilia e estimula a identificar ou

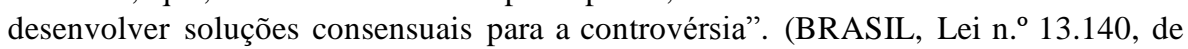
26 de junho de 2015).

Os benefícios da mediação para os indivíduos são muitos, dentre eles destacam-se o empoderamento, a restauração da comunicação, celeridade, baixo custo, entre outros. 
A mediação de pares ou entre pares se caracteriza pela capacitação de alunos, professores e coordenadores para realizarem a mediação entre eles próprios, alunos com alunos e/ou entre os próprios educadores, e não apenas somente entre alunos. (PACHECO, 2006, p. 172).

Tem por objetivo gerenciar melhor os conflitos na escola e apresenta no rol dos benefícios a criação de vínculos cooperativos, senso de comunidade na escola, desenvolvimento do senso de coletividade, melhoria do ambiente em sala de aula, e dentro da escola como um todo, incentivo a valores e responsabilidades e diminuição dos conflitos menores. Neste tipo de mediação é possível o trabalho dos sentimentos e interesses, de forma individual, diretamente entre os envolvidos em determinado conflito, permitindo que o empoderamento seja mais amplamente trabalhado nos indivíduos, senão vejamos:

\begin{abstract}
Consideramos, de facto, que, idealmente, a mediação deverá ser construída por pares; pares porque indivíduos da mesma faixa etária e com a mesma função na escola e pares porque constituem grupos de $2+2$ ( 2 alunos mediadores +2 alunos em conflito). A oferta de um ambiente de aprendizagem seguro e de um clima de bemestar deve estar presente em todas as instituições educativas escolares, de qualquer nível de ensino. Esse deve constituir o principal objectivo de qualquer liderança organizacional. Consequentemente, é criado na escola um ambiente mais positivo (através do desenvolvimento de relações de amizade) e mais propício ao ensino e à aprendizagem 195 com sucesso, até pela íntima relação da mediação com a prática lectiva, que a par da redução da violência e da indisciplina dos alunos constituem talvez as vantagens primordiais desta estratégia; transformando-a numa estratégia preventiva de conflitos. (PACHECO, 2006, p. 172).
\end{abstract}

Como afirmado anteriormente, dentre os benefícios alcançados pela mediação está o empoderamento.

Empoderar é capacitar as partes envolvidas em um conflito para construírem elas próprias as soluções viáveis para solução da controvérsia, com base em diálogos produtivos e comunicação eficiente.

A capacitação dos mediandos em suas narrativas, identificação de expectativas e reais interesses são verificadas e levantadas inicialmente para, primeiro, transformar o conflito ou restaurar a relação anteriormente rompida e só depois, passar a construir um acordo. (VASCONCELOS, 2008, p. 38).

O desenvolvimento de um procedimento educativo, orientado pelo entendimento, caracteriza o empoderamento das partes no processo da mediação e liga o tema à teorias comunicativas já há muito propagadas pela filosofia.

Habermas defendia a busca do sentido emancipatório das ações humanas através de uma interação linguística. $\mathrm{O}$ agir comunicativo apresentado por esse filósofo passa a ser a 
mediação necessária à formação cultural e ao autodesenvolvimento das pessoas em atitude de interação. As interações devem se orientar pelo entendimento e explicitarem-se pela aceitabilidade dos atos de fala, onde cada participante expõe a força ilocucionária de seu proferimento. (HABERMAS, 1989, p.41).

Nessa perspectiva a educação deve se orientar pelo enfrentamento crítico da racionalidade para alimentação da aprendizagem social ante o desenvolvimento de competências de comunicação que conduzam os indivíduos ao entendimento argumentativo com outras pessoas na interação da linguagem.

\footnotetext{
O mundo da vida é, por assim dizer, o lugar transcendental em que o falante e o ouvinte se encontram; é o lugar em que podem estabelecer reciprocamente a pretensão de que suas emissões concordam com o mundo objetivo, subjetivo e social; e em que podem criticar e exibir os fundamentos das respectivas pretensões de validade, resolver seus desentendimentos e chegar a um acordo. (HABERMAS, 1989, p. 179).
}

De uma forma geral, ocorre o empoderamento quando ambos os envolvidos fortalecem seus conhecimentos sobre seus próprios valores e habilidades de lidar com as dificuldades que se depararem. (BUSH, 2005, p. 312).

Pretende-se com o empoderamento das partes, no processo da mediação escolar entre pares, resgatar a responsabilidade de cada um na autoria e na definição de soluções dos conflitos, utilizando-se, para tanto, de um procedimento restaurativo de habilidades comunicacionais pautadas não só em direitos, mas sim em valores, necessidade e interesses.

O objetivo maior será a satisfação recíproca e a sensação de justiça entre os próprios usuários do procedimento.

Assim, deixa-se de lado a tradução da vontade do Estado-Juiz ou legislador para o caso concreto e privilegia-se a vontade das partes envolvidas no conflito com base em suas relações culturais e sociais.

\section{OS DIREITOS FUNDAMENTAIS E A DIGNIDADE HUMANA PRESENTES NO PROCESSO DE EMPODERAMENTO DA MEDIAÇÃO ESCOLAR}

As experiências traumáticas das guerras mundiais, mais especificamente posteriores à Segunda Guerra Mundial, resultaram no surgimento da defesa de direitos universais do ser humano. A dignidade humana, nesse contexto, encontra amplo campo para discussões em função dos movimentos nazistas, fascistas e barbaridades cometidas na período da segunda guerra mundial e também que a sucederam. Inúmeras críticas emergiram em função dessa 
situação ao positivismo jurídico, tão indiferente aos valores éticos e presos a uma ótica meramente formal, que corroborou com as atrocidades praticadas. (PIOVESAN, 2012).

Daí emerge O Direito Internacional dos Direitos Humanos e novas formas de Direito Constitucional Ocidental quando os legisladores são, então, impulsionados a elaborar normas dentro de concepções voltadas a observância da garantia da dignidade da pessoa humana.

Da Declaração de Direitos do Homem, realizada pela ONU, aos diversos pactos, conferências e protocolos, seguiram-se constituições cada vez mais comprometidas com tais direitos. Aos direitos de primeira geração (ou dimensão), a exemplo dos direitos políticos, de liberdade e civis, seguiram-se os de segunda geração como direitos de igualdade, sociais e econômicos, e os de terceira geração que dizem respeito aos povos, culturas, natureza e, ainda, os de quarta geração ou dimensão, que seriam os direitos de gerações futuras.

As dimensões marcam a evolução do processo de reconhecimento e afirmação dos direitos fundamentais demonstrando que são ainda categorias abertas e mutáveis sobretudo por criações jurisprudenciais e transmutações hermenêuticas.

Liberdade e autonomia se conectam e se vinculam a um princípio universal de moralidade que passa a fundamentar as ações humanas, estabelecendo-se a partir daí a trindade igualdade, liberdade e universalidade como direitos humanos a serem implementados na humanidade e que são, então, absorvidos pelas constituições dos Estados modernos.

Dessa forma, firma-se uma fundamentação ética dos direitos humanos que consiste o reconhecimento de condições que são imprescindíveis para a garantida de uma vida digna, caracterizando-se como um princípio vetor do ordenamento jurídico. (RAMOS, 2015).

Ingo Wolfgang Sarlet trata o principio da universalidade como implícito em nossa Constituição e responsável pela interpretação de que todas as pessoas, pelo fato de serem pessoas, são titulares de direitos e deveres fundamentais, sendo, no entanto, reservados, em nossa Constituição, direitos próprios aos naturais ou naturalizados em relação aos estrangeiros. (SARLET, 2006, p.211).

É também o que Fábio K. Comparato defende, ao afirmar:

O que se conta, nestas páginas, é a parte mais bela e importante de toda a História: a revelação de que todos os seres humanos, apesar das inúmeras diferenças biológicas e culturais que os distinguem entre si, merecem igual respeito, como únicos entes no mundo capazes de amar, descobrir a verdade e criar a beleza. É o reconhecimento universal de que, em razão dessa radical igualdade, ninguém - nenhum indivíduo, gênero, etnia, classe social, grupo religioso ou nação - pode afirmar-se superior aos demais. (COMPARATO, 2003, p.1).

A Constituição Brasileira de 1988, pioneira na abordagem dos direitos fundamentais, de forma ampla no Brasil, apresenta-os no Título II, artigos $5^{\circ}$ ao 17 ; e capítulos I a V, sem 
prejuízo de outros. No artigo $5^{\circ}$ se identificam os direitos individuais e coletivos, diretamente ligados ao conceito de pessoa humana e sua personalidade; a partir do artigo $6^{\circ}$ são elencados os direitos sociais, com a finalidade de melhoria de condições de vida aos hipossuficientes, visando a concretização da igualdade social e que configura os fundamentos do Estado Democrático de Direito; no artigo 14, a Constituição apresenta os direitos políticos, aqueles que permitem que o indivíduo possa realizar exercício concreto de liberdade de participação nos temas do Estado.

Os direitos fundamentais sociais a prestações, diversamente dos direitos de defesa, objetivam assegurar, mediante a compensação das desigualdades sociais, o exercício de uma liberdade e igualdade real e efetiva, que pressupõem um comportamento ativo do Estado, já que a igualdade material não se oferece simplesmente por si mesma, devendo ser devidamente implementada.

Assim afirma, Flávia Piovesan, ao discorrer:

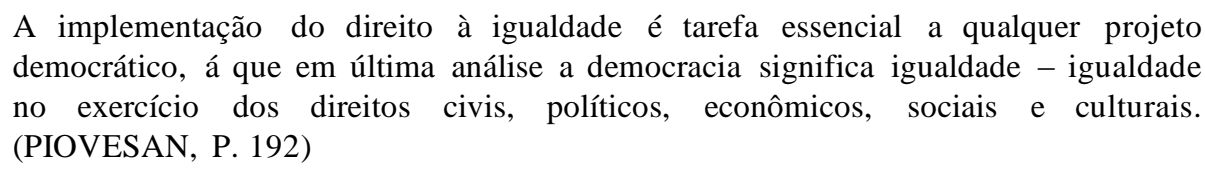

Compete ao Estado a promoção dos direitos materiais fundamentais garantidores da igualdade e liberdade, ficando evidenciada sua responsabilidade em implementar e manter atividades que garantam o desenvolvimento da cidadania nos indivíduos.

Vários tratados internacionais abordam a temática, como se pode confirmar com a leitura do artigo $8^{\circ}$ da Declaração da ONU, trazido ao texto, a seguir transcrita:

Os Estados devem tomar, em nível nacional, todas as medidas necessárias para a realização do direito ao desenvolvimento, e devem assegurar igualdade de oportunidade para todos no acesso aos recursos básicos, educação, serviços de saúde, alimentação, habitação, emprego e distribuição equitativa da renda.

O Pacto Internacional Relativo aos Diretos Econômicos, Sociais e Culturais, aborda, no artigo 13, o reconhecimento pelos Estados à educação para todas as pessoas. Esta, por sua vez, deve visar ao pleno desenvolvimento da personalidade humana e do sentido da sua dignidade. O Brasil recepciona esse pacto, após sua aprovação pelo Decreto Legislativo n. 226 de 12/12/91, com sua promulgação através do Decreto Presidencial n. 591 de 06/07/92, confirmando a amplitude e compromisso com a educação e capacitação das pessoas para a convivência pacífica entre os cidadãos, os povos e as nações. 
Nesse aspecto, a prática da mediação escolar, com o processo educativo do empoderamento entre os indivíduos, insere-se como um importante campo do direito fundamental social, pois promove a construção de ambiente saudável aos jovens e agentes educacionais, mas também garante um direito político, posto que fomentador da cidadania ao educar os cidadãos à superação de conflitos de forma harmonizada, tornando-os aptos à uma convivência pacífica, igualitária e libertadora.

As decisões passam, após o empoderamento, a ser fundamentadas e conscientes de suas consequências e benefícios por todos os integrantes do processo. Preservam-se a vontade, os relacionamentos anteriores, os anseios e os interesses envolvidos por seus participantes, o que representa o pleno desenvolvimento da igualdade de oportunidades e do exercício de cidadania.

\footnotetext{
Assim sendo, temos por dignidade da pessoa humana a qualidade intrínseca e distintiva reconhecida em cada ser humano que o faz merecedor do mesmo respeito e consideração por parte do Estado e da comunidade, implicando, neste sentido, um complexo de direitos e deveres fundamentais que assegurem a pessoa tanto contra todo e qualquer ato de cunho degradante e desumano, como venham a lhe garantir as condições existenciais mínimas para uma vida saudável, além de propiciar e promover sua participação ativa e co-responsável nos destinos da própria existência e da vida em comunhão com os demais seres humanos, mediante o devido respeito aos demais seres que integram a rede da vida. (SARLET, 2012, p.73).
}

A definição trazida ao texto, do escritor Ingo W. Sarlet, demonstra que a relação entre a dignidade da pessoa humana e os direitos fundamentais são indissociáveis. Até mesmo nas normas em que não houver essa referência, somente por isso, não se pode concluir que tal relação não está presente uma vez que em cada direito fundamental há um conteúdo ou alguma projeção da dignidade da pessoa humana.

\footnotetext{
Como tarefa (prestação) imposta ao Estado, a dignidade da pessoa reclama que este guie as suas ações tanto no sentido de preservar a dignidade existente, quanto objetivando a promoção da dignidade, especialmente criando condições que possibilitem o pleno exercício e fruição da dignidade, sendo portanto dependente ( a dignidade) da ordem comunitária, já que é de se perquirir até que ponto é possível ao indivíduo realizar, ele próprio, parcial ou totalmente, suas necessidades existenciais básicas ou se necessita, para tanto, do concurso do Estado ou da comunidade (este seria, portanto, o elemento mutável da dignidade), constatação esta que remete a uma conexão com o princípio da subsidiariedade, que se assume uma função relevante também nesse contexto. (SARLET, 2012. p. 58).
}

Os Direitos fundamentais são, assim, consagrados como exigência e concretizações do princípio da dignidade da pessoa. A dignidade da pessoa humana, por sua vez, na condição de valor fundamental trás como exigência e pressuposto, o reconhecimento e a proteção dos 
direitos fundamentais de todas as dimensões. E todos os direitos fundamentais possuem, também, um fundamento na dignidade da pessoa humana.

\section{CONCLUSÃO}

A escola, enquanto ambiente gerador de processo educativo, é vista como uma instituição social e histórica, onde são geradas transformações nas consciências individuais e, em nível mais amplo, nas sociedades. O indivíduo é considerado capaz de refletir sobre a realidade e atuar nela ao mesmo tempo, transformando-a.

Por sua amplitude de relações, próprias a esse ambiente rico das mais diversas relações, a escola enfrenta, ordinariamente, conflitos diários e das mais diversas e amplas formas.

Os conflitos, vistos sob o enfoque positivo, podem prevenir estagnações, impulsionar soluções criativas e estabelecer relacionamentos sobre novos patamares de equilíbrio e convivência harmônica. Eles fazem parte de um processo natural da convivência humana e sua superação pode significar uma política positiva de gestão voltada a encontrar soluções calcadas na capacidade da escola e de seus agentes em vencer as situações conflituosas sem esmagar os alunos e demais participantes do ambiente sob o peso da violência institucional e simbólica.

Essa superação, nessa base, será bem atendida com a utilização da mediação escolar e, mais especificamente, entre pares, vez que nesse tipo de mediação desenvolve-se, individualmente e mais facilmente, as habilidades de diálogos produtivos em ambos os indivíduos, em ambiente e processo seguros, gerando um clima de bem estar que deve estar presente em todo ambiente escolar.

A mediação entre pares, ao constituir grupos de dois em dois em seu procedimento (aluno-aluno, professor-professor, coordenador-coordenador), com a mesma função, mesmo grau de hierarquia, oferta ambiente com aprendizagem mais segura e efetiva, surgindo, assim, ações propícias ao pleno desenvolvimento de relações de amizade e respeito.

Isso faz da mediação escolar uma estratégia preventiva de conflitos e importante meio de sua superação sem qualquer imposição, mas sim através de construções das próprias partes envolvidas no processo.

Além de ser um processo educacional, que capacita as pessoas para enfrentarem situações de litígio de forma direta e objetiva, a mediação promove a superação, com enfoque 
prospectivo e com uso de diálogo respeitoso, regrado e conduzido com bastante cuidado, não somente daquele conflito em análise, como também da maior parte dos conflitos futuros, de forma pacífica. A esse processo educacional, promovido na mediação, chamamos Empoderamento dos indivíduos.

Ao educar os indivíduos com o diálogo equilibrado e controlado, o ambiente escolar estará atendendo aos direitos fundamentais garantidores da igualdade, liberdade e fraternidade previstos na Declaração dos Direitos Humanos e diversos pactos internacionais e, ainda, presentes em nossa Constituição Federal de 1988, que garante amplos direitos sociais e políticos aos indivíduos.

Cabe ao Estado a promoção de atividades, educativas, econômicas e sociais, que possam desenvolver outras habilidades complementares necessárias para que se tornem capazes de agir e interagir em sociedade de forma urbana e sociável.

A mediação, nesse contexto, como política pública, poderia ser implementada, por meio de cursos dos profissionais e demais agentes do meio escolar e apoio institucional para sua ampla realização, gerando excelentes resultados a baixos custos.

Esses direitos fundamentais, representam a concretização do princípio da dignidade da pessoa humana, que tem por pressuposto a proteção aos direitos fundamentais em todas as suas dimensões.

Sendo a escola um locus disseminador, impulsionador e estimulador dos comportamentos, é este o ambiente ideal para a disseminação da prática da mediação e promoção do empoderamento nos indivíduos, vez que tende a ser um comportamento reproduzido em sociedade com bons resultados e de fácil implantação.

\section{REFERÊNCIAS}

BRASIL, CONSELHO NACIONAL DE JUSTIÇA. Azevedo André Gomma de (Org) Manual de Mediação Judicial, $5^{\mathrm{a}}$ ed.(Brasilia/DF:CNJ), 2015.

BRASIL. Constituição (1988). Constituição da República Federativa do Brasil. Casa Civil. Subchefia para assuntos jurídicos. Diário oficial da república federativa do Brasil, Brasília, DF. Disponível em: http://planalto.gob.br/ccivil_03/constituição.htm. Acesso em 18 de agosto de 2015.

BRASIL. Lei 13.105/2015, Artigo 165, §3º.http:/www.planalto.gov.br/ccivil_03/ _ato2015.2018/2015/lei/13105.htm.acesso em 20/03/2016.) 
BRASIL. Lei n. ${ }^{\circ}$ 13.140, de 26 de junho de 2015. Disponível em: . Acesso em: 08 jul. 2015

BUSH, Robert A. Baruch: FOLGER, Joseph P. The promise of mediation. In Menkel- meadow, Carrie J; Love, Lela Porter; Schneider, Andrea Kupfer, Sternligth, Jean R. Dispute Resolution: Beyond the Adversarial Model Nova York: Aspen Publishers, 2005.

CHARLOT, Bernard. A Violência na escola: como os sociólogos franceses abordam essa questão. Sociologias, Porto Alegre, ano 4, $\mathrm{n}^{\circ}$ 8, Juldez, 2002, p. 432-443. Disponível em: http://www.scielo.br/pdf/soc/n8/n8a16, acesso em 19-03-2016).

COMPARATO, Fábio Konder. A Afirmação histórica dos direitos humanos. 3 ed. - São Paulo: Saraiva, 2003.

Meus Dicionários Online, disponível em (http://www.meusdicionarios.com.br/empowerment, acesso em 21/03/2016)

DIMAS, I. D.; LOURENÇO, P. R.; MIGUEZ, J. Conflitos e desenvolvimento nos grupos e equipas de trabalho: uma abordagem integrada. In: DIMAS, I. D. et. al.. (Re) Pensar os conflitos intragrupais: desempenho e níveis de desenvolvimento. Lisboa, v.21, n.2, 2007. Disponível em<http://www.scielo.gpeari.mctes.pt/scielo.php?script=sci _arttext\&pid=S08740492007000200011\&lng=pt\&nrm=iso>. acessos em 21 jan. 2016

DEUSTSCH. Morton. A resolução do Conflito. In: AZEVEDO, André Gomma de (org.). Estudos em Arbitragem, Mediação e Negociação. Vol 3. Brasília: Grupos de Pesquisa, 2004.p. 29 a 98.

FOLLET. M. P. Constructive Conflict, in. P. Graham (ed.), A Celebracion of Writing from the. Boston, Harvard Business School Press, 1996.

GIL, Antônio Carlos. Como elaborar projetos de pesquisa. 4.ed. São Paulo: Atlas, 2008.

GOLDBERG, Stephen B., SANDER, Frank E.A ., ROGERS, Nancy H., COLE, Sarah R. Dispute Resolution - Negociation, Mediation, and Other Processes, $4^{\mathrm{a}}$ edition, New York:Aspen Publishers, Inc, 2003, p.111.

HABERMAS, Jurgen. Consciência Moral e Agir Comunicativo. Rio de Janeiro: Tempo Brasileiro, 1989.

MOORE, Christopher W. O processo de mediação: estratégias práticas para a resolução de conflitos. 2. ed. Porto Alegre: Artmed, 1998.

MUNOZ, Helena Soleto. La Mediación: Método de Resoluición Alternativa de Conflitos em el Proceso Civil Español, in: Revista Eletrônica de Direito Processual, ano 3, vol. 3, janeiro a junho de 2009, disponível no site http:www.redp.com.br., acesso em fevereiro de 2015.

ONU. Declaração e Programa de Ação sobre uma Cultura de Paz. www.comitepaz.org.br/dec_prog_1.htm.211mar2016 às 21:12hs. 
ORSINI, A. et. al. RECAJ nas escolas: promoção de cidadania e formas alternativas de resolução de conflitos no ambiente escolar. Revista extensão, Cruz das Almas, BA: Universidade Federal do Recôncavo da Bahia, Pró-Reitoria de Extensão. v.3, n.1, p.191 -201, setembro/2012. Disponível em www.ufrb.edu.br/revistaextensao/index.../download. Acesso em 30 de março de 2016.

PACHECO, Florinda Maria Coelho Pacheco. A Gestão de Conflitos na escola a mediação como alternativa. Dissertação para obtenção de grau em Mestre em Administração e Gestão Educacional. Lisboa, 2006.

PIOVESAN, Flávia. Temas de Direitos Humanos. 3.ed. São Paulo: Saraiva, 2009.

Saraiva, 2012.

Direitos Humanos e o direito constitucional internacional. São Paulo:

RAMOS, André de Carvalho. Teoria geral dos direitos humanos na ordem internacional, 5 ed. São Paulo: Saraiva, 2015.

SARLET, Ingo Wolfgang. Dignidade da pessoa humana e direitos fundamentais na constituição federal de 1988. Editora livraria do advogado. Porto alegre, 2012.

Advogado, 2006.

A eficácia dos direitos fundamentais. 6. Ed. Porto Alegre, Livraria do

VASCONCELOS, Carlos Eduardo de. Mediação de conflitos e práticas restaurativas. São Paulo: Método, 2008. 